\title{
Evidence of primary air pollutant reduction and photochemical pollution enhancement after opening a road tunnel to the public
}

\author{
R. Jiménez, H. van den Bergh and B. Calpini \\ Laboratory of Air Pollution (LPA), Swiss Federal Institute of Technology (EPFL), CH-1015 Lausanne, Switzerland
}

\begin{abstract}
Measurements of local air pollution and road traffic were taken during a period of one month before and after the opening of a road tunnel to the public in nearby Sachseln, a small city located in a rural region (Obwald) at the center of Switzerland. Two 5-day periods of time (before and after the tunnel opening) of equivalent weather and road traffic features were selected for assessing the tunnel impact on air quality. Despite the road traffic across Sachseln dropped by about $50 \%$ after the tunnel opening, its daily profile remained unchanged. After a further time split, statistical analyses allowed determining the modal concentrations of air pollutant at daytime and nighttime (background). Truck traffic was found to be the controlling variable of $P_{10}$ concentration. After the tunnel was opened, daytime concentration of $\mathrm{PM}_{10}, \mathrm{PAH}$ and $\mathrm{NO}_{x}$ dropped by about $50 \%$. On the contrary, the ambient $\mathrm{O}_{3}$ concentration increased by about $35 \%$, probably as a result of reducing $\mathrm{NO}_{x}$ in a VOC-limited regime for ozone formation.
\end{abstract}

\begin{abstract}
- he present work is part of a study on air quality in the Canton of Obwald carried out during the period 19961998 [1]. The Canton of Obwald is an alpine region located at the center of Switzerland. Its main geographic feature is the Saarnerataal, a mainly agriculture-devoted alpine valley, approximately $29 \mathrm{~km}$ long and $5 \mathrm{~km}$ wide [2]. Concern about its air quality comes from the fact road traffic across and inside the Saarnerataal has been increasing at a quite high growing rate during the last years: $8.1 \%$ per year during the period 1986-1989 and currently at $2.9 \%$ per year [3]. In addition, the Saarnerataal is most of the year downwind Luzern and, at special weather conditions, downwind Zurich, two important air pollutant sources.
\end{abstract}

Air and noise pollution due to road traffic were particularly noticeable at Sachseln, a small city located at the middle of the Saarnerataal and crossed by the N4, the most important motorway along the Saarnerataal (see Fig. 1). In an attempt to improve road traffic and to reduce noise and air pollution, a tunnel that bypasses Sachseln was built and finally opened to the public on September 24, 1997. In order to assess its impact on the air quality at Sachseln, a measurement campaign was carried out from September 9 to 


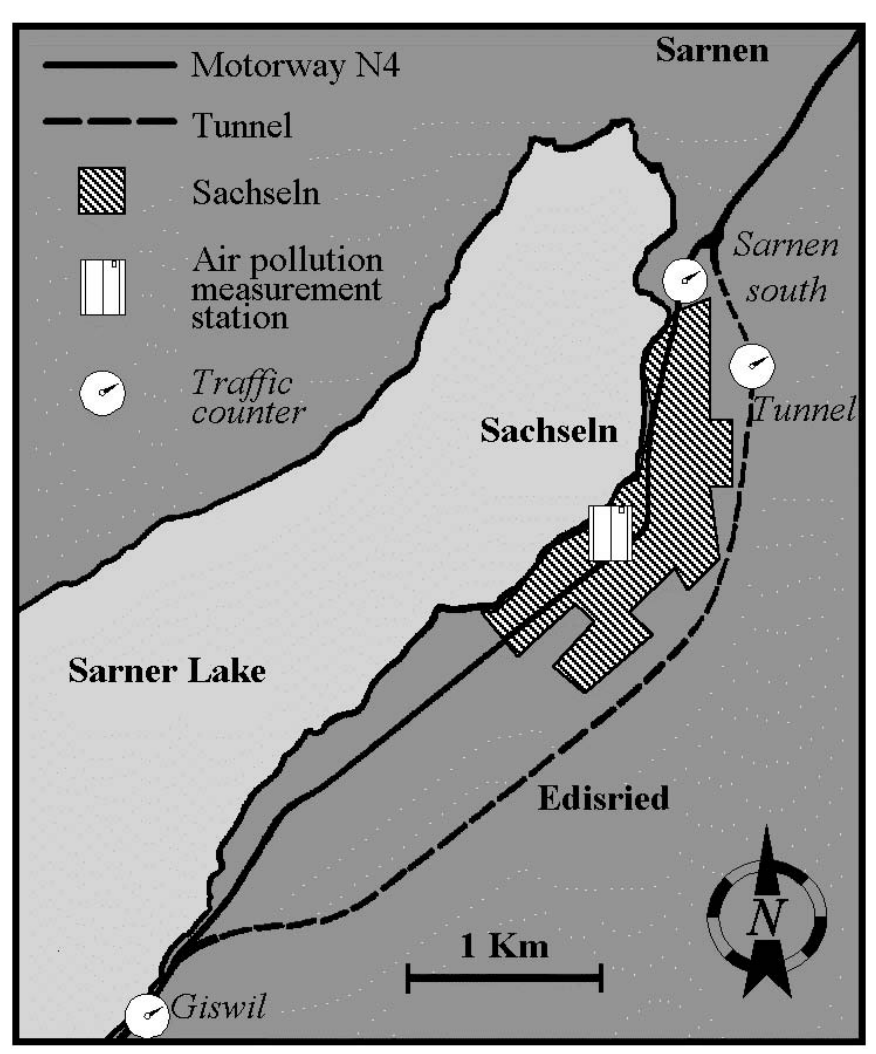

Figure 1. Schematic map of the Sachseln urban area and surroundings, showing the key elements of the tunnel campaign.

October 7, 1997. Drop in local road traffic crossing Sachseln due to the tunnel opening was expected to reduce local concentrations of primary air pollutant at Sachseln. Nevertheless, its impact on air quality on a regional scale is still not clear, since after the tunnel opening, the intensity of an important linear emission source of air pollutant, the motorway N4, was locally reduced but two new point sources appeared at the tunnel ends [4].

\section{Data and methodology of analysis}

During the period September 9 - October 7, 1997, meteorological and air pollutant point measurements were carried out in a ground-based station placed in Sachseln downtown (Swiss coordinates $=661$ 120; 191 280) (See Fig. 1). The meteorological parameters measured (30-minute time resolution) were solar radiation, temperature, relative humidity, wind speed and direction. $\mathrm{O}_{3}, \mathrm{NO}, \mathrm{NO}_{2}$ and $\mathrm{PAH}$ (polycyclic aromatic hydrocarbons) were measured with standard point monitors at a 30-minute time resolution. $\mathrm{PM}_{10}$ (particulate matter of less than $10 \mu \mathrm{m}$ ) and EC (elementary carbon) were measured with a high volume sampler at a time resolution of one day.

In addition, road traffic data was gathered from three traffic counters located at Sarnen South, Giswil and inside the tunnel (see Fig. 1). The counter at Sarnen South provided hourly, size-differentiated traffic data. Since the counter at Giswil (1-hour time resolution) was placed in an intersection, traffic in 5 directions was measured or estimated from measurements. The counter inside the tunnel provided daily traffic measurements.

Despite the air pollutant emissions around Sachseln were spatially redistributed by opening the tunnel, their total quantity remained almost unchanged, i.e. the reduction of emissions achieved in the motorway N4 (linear source) was simply moved to the tunnel ends ( 2 new point sources). This redistribution of emission sources is expected to impact air quality not only around Sachseln but also on a wider zone. Since this study is based on the very local measurements performed during the tunnel-opening period, the validity of the conclusions withdrawn hereafter is restricted to the Sachseln urban zone. Nevertheless, a detailed analysis of the photochemical pollution in the Saarnerataal, based on field measurements, carried out in the summer 1997, and 3-D eulerian simulation is available [1-3]. Further field measurements and simulation, based on an updated emission inventory, will be required to fully assess the tunnel impact on air quality.

Since the processes involved in transforming emissions into air pollutant concentrations are very complex and impossible to be described in simple terms, instantaneous values of emission can hardly be correlated to ground-level instantaneous air pollutant concentrations by simple statistical means. Nevertheless, when the meteorological and emission patterns that give rise to two air pollutant time series are similar, it remains possible to intercompare the two time series and to correlate them to their correspondent emission data sets. The following methodology was applied to the tunnel opening case:

- Two 5-day periods of time, one BEFORE (September 1519, 1997) and another AFTER (September 29 - October $3,1997)$ the tunnel opening were selected. These two time intervals show similar, good weather conditions, thus assuring similarity between the transformation processes taking place. In addition, they comprise the same weekdays (Monday to Friday), thus making similar their daily emission patterns. Finally, they are apart enough to the tunnel opening day, thus avoiding a possible transition period (Fig. 2).

- Changes in solar radiation, temperature, and wind speed and direction were assessed regarding their possible effect on pollutant concentration.

- After statistical analyses, changes in air pollutant concentration were related to changes in road traffic. 


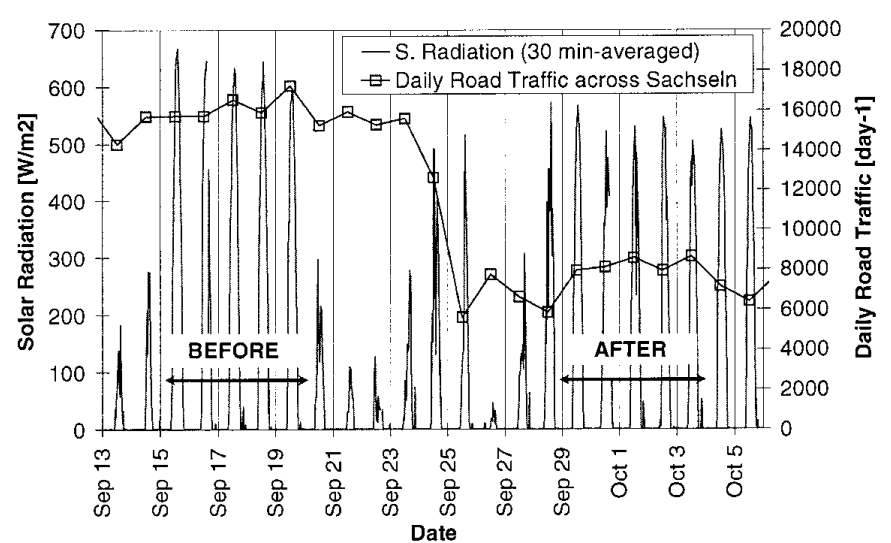

Figure 2. Solar radiation (30-minute average) at Sachseln downtown and daily road traffic at Sarnen south. Selection of the 5day periods before and after the tunnel opening.
Table I. AFTER to BEFORE ratio of solar radiation, temperature and relative humidity and their corresponding correlation coefficients.

\begin{tabular}{lcc}
\hline Parameter & $\begin{array}{c}\text { Ratio AFTER / } \\
\text { BEFORE }\end{array}$ & $\begin{array}{c}\text { Correlation } \\
\text { Coefficient [\%] }\end{array}$ \\
\hline Solar radiation & 0.77 & 91.4 \\
Temperature & 0.97 & 83.5 \\
Relative humidity & 0.99 & 73.8
\end{tabular}

cant differences between the wind roses BEFORE and AFTER. Moreover, the NIGHTTIME modal (most frequent) wind speed at both periods $(0.04 \mathrm{~m} / \mathrm{s})$ is at the level of the anemometer lower detection limit (LDL) [4]. Minor changes BEFORE to AFTER are observed in the DAYTIME wind roses: drift of the modal (most frequent) wind direction (from $330^{\circ}$ to $277^{\circ}$ ), increase of the wind direction scattering, wind speed reduction [4] (see Tab. II). Despite of these differences, air was essentially stagnant during both periods, before and after the tunnel opening, being "calms" (wind speed $<0.5 \mathrm{~m} / \mathrm{s}$ ) the most frequently observed condition.

At the modal wind speed at DAYTIME, a polluted air parcel emitted out the north end of the tunnel would reach the measurement station at Sachseln downtown in approximately 6 hours. Such a time lag is long enough to assure that primary air pollutant measurements at Sachseln downtown were related only to very local emissions. On the contrary, emissions from the tunnel ends are expected to increase background concentrations (indirect effect). Advection at NIGHTTIME was negligible.

\section{Road Traffic}

Two components account for the road traffic in the Sachseln area: the local one, the road traffic that kept riding across Sachseln after the tunnel opening, built up to a stationary, well-defined weekly profile, even during a longer measurement period (September - November 1997). On the other hand, the regional component, the traffic across the tunnel, showed peak rate during weekends and seasonal decrease. Despite these differences, hour-to-hour, Monday-to-Friday averaged daily profiles at BEFORE and AFTER are of essentially identical features, despite a $49 \%$ average reduction of the traffic total volume (see Fig. 3). It must be mentioned that an unexpected resemblance was found between these 3-peak daily profiles at Sachseln and those of principal roads (urban and rural) at Atlanta UAM (USA), analyzed within the SOS Study (July-August 1992) [5]. The normalization of the hourly, daily accumulated traffic volume profiles confirmed that BEFORE and AFTER traffic profiles are equivalent, and showed that $75 \%$ of traffic volume is accumulated at DAYTIME (9:00-20:00) despite of the selected period around the tunnel opening. Accordingly $75 \%$ of the emissions from road traffic took place at DAYTIME.
For unfolding the effect of solar radiation on the local airflow at ground level, two semi-diurnal subsets were selected: DAYTIME (9:00-20:00) and NIGHTTIME (20:00-9:00). Regarding NIGHTTIME, there are not statistically signifi- 
Table II. Summary of statistics on meteorology, road traffic and air pollutant concentration during the selected 5-day periods, before and after the tunnel opening.

\begin{tabular}{|c|c|c|c|c|c|}
\hline \multirow[t]{2}{*}{ Variable } & \multirow{2}{*}{$\begin{array}{c}\text { Semi-diurnal } \\
\text { period }\end{array}$} & \multirow{2}{*}{$\begin{array}{l}\text { Statistical } \\
\text { Descriptor }\end{array}$} & \multicolumn{2}{|c|}{ Period of Time } & \multirow{2}{*}{$\begin{array}{c}\text { Relative } \\
\text { Change [\%] }\end{array}$} \\
\hline & & & BEFORE & AFTER & \\
\hline \multirow[t]{2}{*}{ Wind speed $[\mathrm{m} / \mathrm{s}]$} & DAY-TIME & Median & 0.15 & 0.07 & -53.3 \\
\hline & & Fraction $>0.5 \mathrm{~m} / \mathrm{s}$ & $16.6 \%$ & $17.9 \%$ & +1.3 \\
\hline \multirow[t]{2}{*}{ Road traffic (hourly) $\left[\mathrm{h}^{-1}\right]$} & DAY & Median & 993 & 480 & -51.7 \\
\hline & NIGHT & Median & 161 & 58 & -64.0 \\
\hline Road traffic (daily) [day $\left.{ }^{-1}\right]$ & Non split & Mean & 16.191 & 8.223 & -49.2 \\
\hline Truck traffic (daily) [day $\left.{ }^{-1}\right]$ & Non split & Mean & $1365 \pm 50$ & $541 \pm 21$ & -60.4 \\
\hline $\mathrm{PM}_{10}$ (daily) $\left[\mu \mathrm{g} / \mathrm{m}^{3}\right]$ & Non split & Mean & $43.7 \pm 5.2$ & $31.1 \pm 4.6$ & -28.9 \\
\hline \multirow[t]{3}{*}{$\mathrm{PAH}\left[\mathrm{ng} / \mathrm{m}^{3}\right]$} & DAY-TIME & Median & 23.2 & 11.0 & -52.5 \\
\hline & & Fraction $>20 \mathrm{ng} / \mathrm{m}^{3}$ & $63.0 \%$ & $20.7 \%$ & -42.3 \\
\hline & NIGHT-TIME & Fraction $>10 \mathrm{ng} / \mathrm{m}^{3}$ & $4.0 \%$ & $6.2 \%$ & +2.2 \\
\hline NO [ppb] & DAY & Median & 26.6 & 12.9 & -51.5 \\
\hline $\mathrm{NO}_{2}[\mathrm{ppb}]$ & DAY & Median & 18.6 & 13.2 & -28.8 \\
\hline \multirow[t]{3}{*}{$\mathrm{NO}_{x}[\mathrm{ppb}]$} & DAY-TIME & Median & 48.0 & 27.2 & -43.3 \\
\hline & & Mode & 63.8 & 30.4 & -52.4 \\
\hline & NIGHT & Median & 4.8 & 4.7 & -2.1 \\
\hline \multirow[t]{3}{*}{$\mathrm{O}_{3}[\mathrm{ppb}]$} & DAY-TIME & Median & 15.8 & 21.3 & +34.7 \\
\hline & & Mode & 18.5 & 31.7 & +71.5 \\
\hline & NIGHT & Median & 12.3 & 13.4 & +8.4 \\
\hline
\end{tabular}

Concerning the traffic volume, it can be observed that the tunnel was more efficient in diverting truck than car traffic. The first one was reduced by $48 \%$ and the second one by $60 \%$. See table II.

\section{Air pollutant concentration}

$\mathrm{PM}_{10}$ daily concentration was reduced by $29 \%$ from BEFORE to AFTER (see Tab. II). Despite only 10 experimental data points (two 5-day periods) were available, its dependence upon road traffic was investigated by applying 3 different linear models [6], involving the daily volume of either cars $(<5.5 \mathrm{~m})$, short $(5.5-8.0 \mathrm{~m})$ and/or large trucks $(>8.0 \mathrm{~m})$. Figure 4 shows the simplest but also the statistically more robust of them. These models show that $\mathrm{PM}_{10}$ was proportional to road traffic, and provide an estimation of the $\mathrm{PM}_{10}$ background concentration, i.e. the one would be obtained after reducing the road traffic across Sachseln to zero. This value was closely estimated in the 20.8 $22.7 \mu \mathrm{g} / \mathrm{m}^{3}$ range by the three models. By using the fitting coefficients it can be estimated that a truck $(>5.5 \mathrm{~m})$ contributed 16-21 times more than a car in building up the $\mathrm{PM}_{10}$ concentration. Relative to its background concentration, the $\mathrm{PM}_{10}$ concentration was reduced by $60.0 \%$, an essentially identical reduction to the one achieved on daily truck volume $(60.4 \%)$.

For assessing changes in $\mathrm{PAH}, \mathrm{NO}_{X}$ and $\mathrm{O}_{3}$ due to the tunnel opening, a simple comparison of their concentration histograms before and after the tunnel opening was found to be a statistically more robust approach than a direct corre-

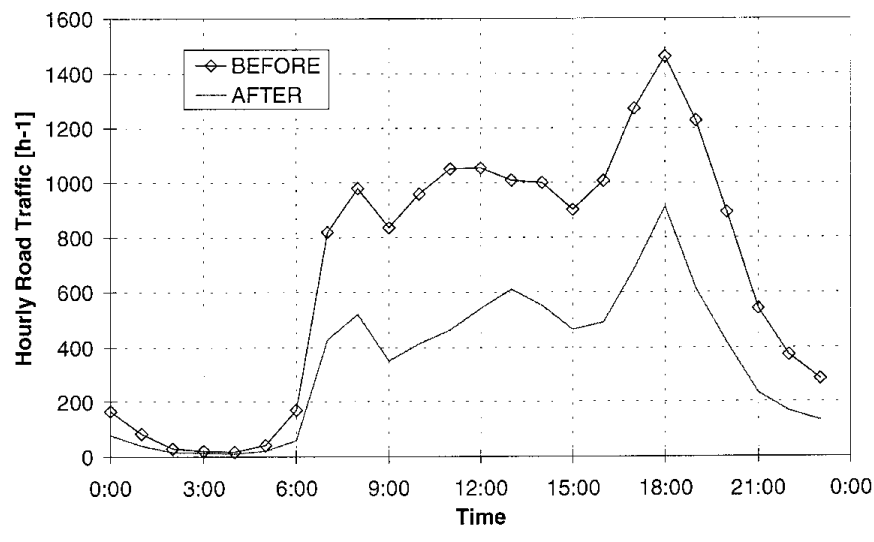

Figure 3. Weekday profile of road traffic at Sarnen south during the BEFORE and AFTER period of time. Each profile is an hourto-hour, 5-day (Monday to Friday) average.

lation to road traffic. Continuous histograms were estimated by means a computer program that traces a probability density function (PDF) by using of a rational smearing function [4].

The polycyclic (or polynuclear) aromatic hydrocarbons (PAH) are a set of combustion-generated air pollutants. Since these compounds are direct-acting mutagens [7], their control is of the highest interest from the point of view of 


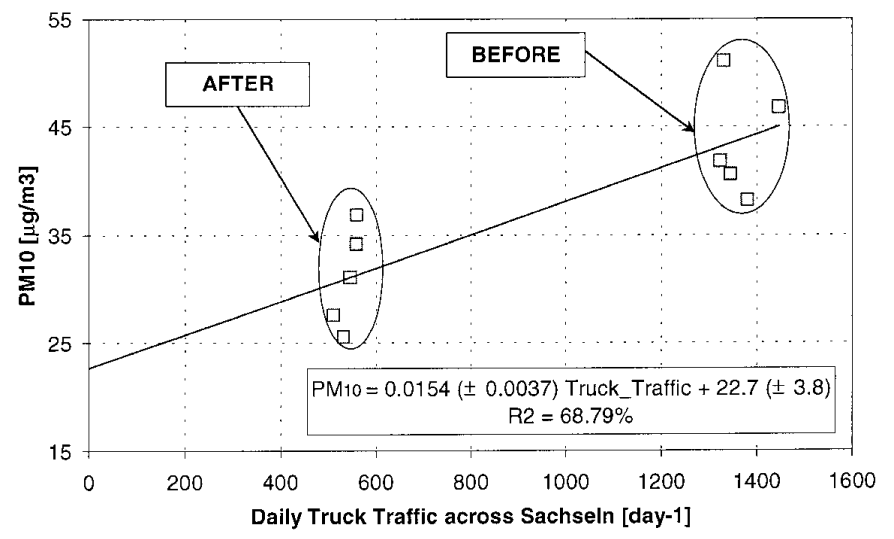

Figure 4. Correlation of $\mathrm{PM}_{10}$ at Sachseln downtown to truck traffic at Sarnen south. Both variables are daily averages.

public health. As expected, the reduction of the local traffic volume across Sachseln led to an outstanding reduction of the local concentration of PAH (see Tab. II). It must be remark that the PAH concentration at DAYTIME was reduced essentially to same extent $(52.5 \%)$ than the road traffic at DAYTIME $(51.7 \%)$. Since PAH is a primary pollutant such linearity of its response to the road traffic reduction was expected.

The histograms of the $\mathrm{NO}, \mathrm{NO}_{2}, \mathrm{NO}_{X}$ and $\mathrm{O}_{3}$ time series at BEFORE and AFTER happened to be bimodal and to fit fairly well a theoretical bimodal log-normal distribution [7]. See figure 5A. A hypothesis was made stating that the two modes of a concentration histogram are related to day and nighttime concentrations. In order to test this hypothesis, the air pollutant time series were further split in DAYTIME and NIGHTTIME, the same time split formerly applied to the wind direction and speed and PAH time series (see Fig. 5B). This hypothesis was proven to be valid for the $\mathrm{NO}_{X}$ compounds, but less successful in decoupling the two modes of the $\mathrm{O}_{3}$ histogram. The fact that a time lag exists between the time series of $\mathrm{NO}_{X}$ and $\mathrm{O}_{3}$ explain this finding.

As expected the reduction of NO $(51.5 \%)$, a primary air pollutant, followed that one of road traffic (51.7\%). A lower reduction was achieved on $\mathrm{NO}_{2}(28.8 \%)$, both a primary and secondary air pollutant (see table II). The fact this reduction did not follow that one of the traffic shows that the relation between precursors and secondary pollutants is non-linear. This is particularly true for ozone. In this case, a $51.7 \%$ reduction of the road traffic led to a $34.7 \%$ increase of the $\mathrm{O}_{3}$ concentration (median values) (see Tab. II). Moreover, this increase was observed in a period (AFTER) when solar radiation was $23 \%$ lower than at the reference period (BEFORE). This reduction on the photolysis rate should lead to an ozone reduction, which was not the case.

Since the Saarnerataal is a rural region, the $\mathrm{O}_{3}$ concentration in the Sachseln area is likely $\mathrm{NO}_{X}$-controlled, i.e. the
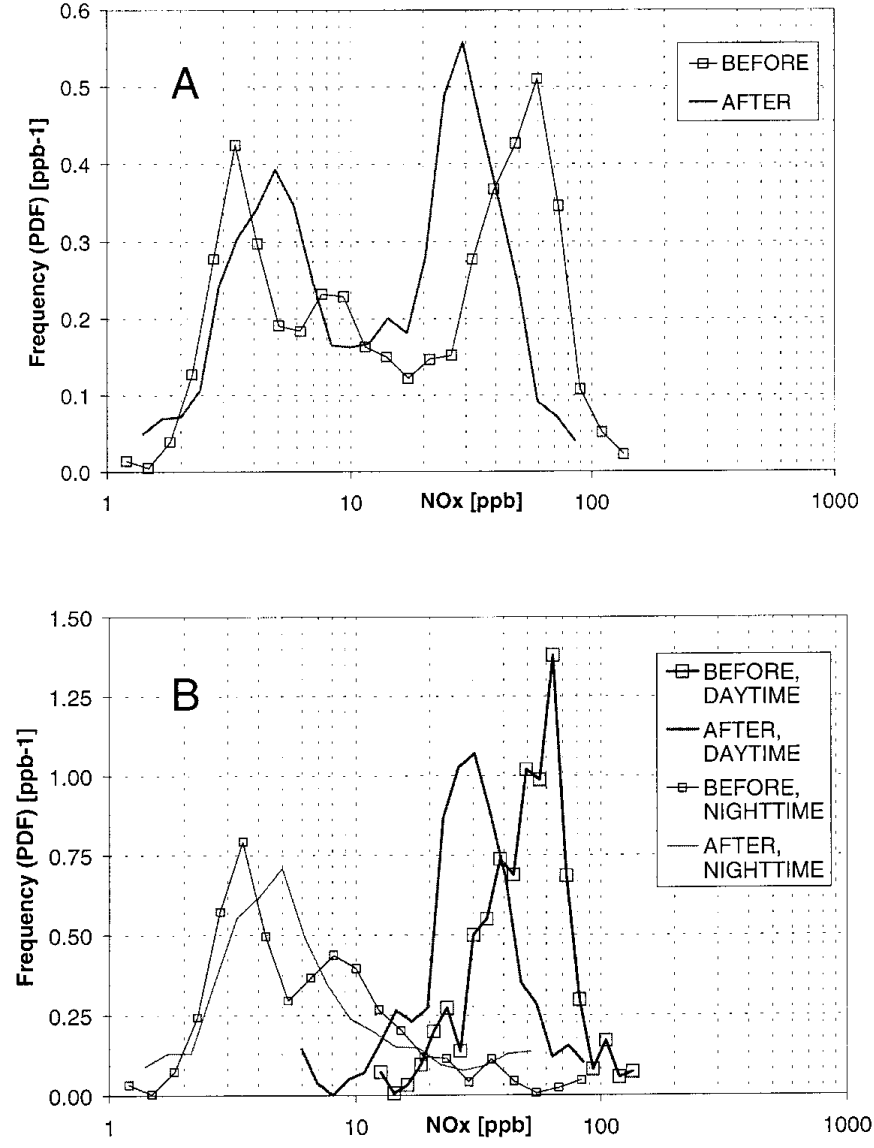

Figure 5. Frequency distribution (histograms) of $\mathrm{NO}_{x}$ concentration during the BEFORE and AFTER periods of time. A. Entire (non-split) 5-day time series. B. After splitting the 5-day periods in DAYTIME (9:00-20:00) and NIGHTTIME (20:00-9:00).

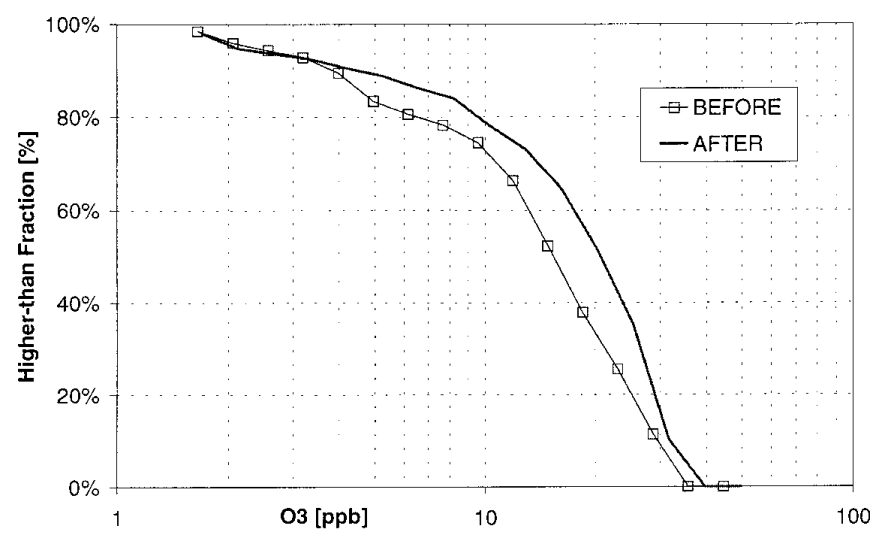

Figure 6. Probability plot of the $\mathrm{O} 3$ concentration at DAYTIME (9:00-20:00) during the BEFORE and AFTER periods of time.

concentration of $\mathrm{O}_{3}$ should decrease by reducing the $\mathrm{NO}_{X}$ emission. Nevertheless, the observed $\mathrm{O}_{3}$ increase is referred 
to a reduction on very local emissions. $\mathrm{O}_{3}$ production inside the motorway emission plume is probably VOC-controlled, as usual in fresh urban plumes. In this case, a reduction of the NO emission of would lead to increase the $\mathrm{O}_{3}$ concentration, simply because of the reduction of the extent of the $\mathrm{O}_{3}$ titration reaction $\left(\mathrm{NO}+\mathrm{O}_{3} \rightarrow \mathrm{NO}_{2}+\mathrm{O}_{2}\right.$ ).

\section{Conclusions}

A preliminary assessment of the impact of a new road tunnel on air quality was performed by applying a simple statistical methodology to two 5-day periods, before and after the tunnel opening. This analysis shows the substantial impact a spatial redistribution of emissions may have on air quality.

Truck traffic was found to be the controlling variable of $\mathrm{PM}_{10}$ in Sachseln. It was found that a truck contributes up to 21 times more than a car in building up this pollutant ambient concentration. The $\mathrm{PM}_{10}$ background concentration, i.e. the one would be achieved after reducing the traffic across Sachseln to zero, was estimated at $22 \mu \mathrm{g} / \mathrm{m}^{3}$. Referred to this baseline, the $\mathrm{PM}_{10}$ concentration was reduced by $60 \%$ after the tunnel opening, essentially the same reduction achieved on the volume of trucks that cross Sachseln. The other primary pollutant measured, $\mathrm{PAH}$ and $\mathrm{NO}$, followed in a similar way the reduction achieved in the total traffic.

The concentration histograms of $\mathrm{O}_{3}$ and the $\mathrm{NO}_{X}$ compounds happened to be bimodal. The concentration modes in the $\mathrm{NO}$ and $\mathrm{NO}_{X}$ histograms were easily decoupled by applying a simple time split, which shows that the higher concentrations of these pollutants take place at DAYTIME (9:00-20:00), the period of the day that accumulates $75 \%$ of the emissions from road traffic.
The fact ozone increased by $35 \%$ after reducing by $52 \%$ the emissions from road traffic underlines the non-linearity of the ozone production process. It is very likely that this increase was the result of reducing the $\mathrm{NO}_{X}$ content in a fresh (VOC-limited) motorway emission plume. Further measurement and simulation efforts will be required to substantiate this affirmation and to fully assess the tunnel impact on the Saarnerataal air quality.

\section{Acknowledgements}

This research is part of the project Air Quality in the Canton of Obwald, funded by the same canton. The authors gratefully acknowledge the contribution of Dr. Guy Défayes, regarding the conception and management of the tunnel campaign.

\section{References}

1. Calpini, B.; Perego, S.; Jiménez, R.; Larchevêque, G.; van den Bergh, H. Die Luftqualität im Kanton Obwalden. Schlußbericht, LPA/EPFL, Lausanne, Jun. 1998.

2. Jiménez, R.; Dubois, C.; Jeanneret, F.; Larchevêque, G.; Lazzarotto, B.; Simeonov, V.; Calpini, B. Assessment of air quality in the Canton of Obwald. Field Measurement Campaign 1997. Preliminary Experimental Report, LPAS/EPFL, Lausanne, Nov. 1997.

3. Chevrau, L. M. Sc. Thesis, LPAS/EPFL, Lausanne, Feb. 1997.

4. Jiménez, R.; Calpini, B.; van den Bergh, H. Assessment of the impact of a new tunnel on air quality in the city of Sachseln (Obwald). LPAS/EPFL, Lausanne, Feb. 1998.

5. Cardelino, C. J. Air Waste Manage. Assoc. 1998, 48, 637-645.

6. Russell, A. G. In Air Pollution, the automobile, and public health; Watson, A. Y. et al., National Academy Press Washington, 1988; pp 167-169.

7. Seinfeld, J. H. Atmospheric chemistry and physics of air pollution. John Wiley: New York, 1986; pp 31-36, 669-673. 